\title{
Categories, stereotypes, and the linguistic perception of sexuality
}

\author{
E R E Z L E V O N \\ Queen Mary University of London \\ Department of Linguistics \\ Mile End Road, London E1 4NS, UK \\ e.levon@qmul.ac.uk
}

\section{A B S T R A C T}

This article examines how social stereotypes influence listeners' perceptions of indexical language. Building on recent developments in linguistics and social psychology, I investigate the extent to which stereotypical attitudes and beliefs about categories of speakers serve to enable the association of linguistic features with particular social meanings while simultaneously blocking others. My arguments are based on an analysis of listener perceptions of the intersecting categories of gender, sexuality, and social class among men in the UK. Using a modified matched-guise paradigm to test three category-relevant variables (mean pitch, spectral characteristics of /s/, and TH-fronting), I demonstrate how the perception of social meaning is governed by a combination of both attitudinal and cognitive factors. This finding is important because it illustrates the listener-dependent nature of sociolinguistic perception. Moreover, it also provides further empirical support for an understanding of social meaning as an emergent property of language-in-use. (speech perception, attitudes and stereotypes, sexuality, phonetic variation)*

\section{N T R O D U C T I O N}

Stereotypes have a profound impact on our perceptions of the people we encounter. Research in social psychology over the past forty years has demonstrated that individuals draw on pre-existing beliefs and attitudes about social categories (i.e. stereotypes) when forming initial impressions of others (e.g. Higgins \& Bargh 1987; Macrae \& Bodenhausen 2001), and recent work in linguistics has shown that such category-based perception can also affect how speech itself is processed (e.g. Johnson, Strand, \& D’Imperio 1999; Niedzielski 1999; Hay, Warren, \& Drager 2006). In this article, I examine how stereotypical expectations regarding category membership influence listeners' perceptions of indexical speech. Specifically, I investigate the intersection of perceptions of gender, sexuality, and social class among men in order to determine the extent to which the identification of a speaker as a member of a particular social group (working-class, for example) 
may impede his identification as another (e.g. gay). My goal in doing so is to examine the linguistic perception of sexuality in its wider social context, and, as a result, to contribute to the development of a better understanding of the process through which variants come to evoke social meaning in the course of everyday interaction (Podesva 2007; Campbell-Kibler 2009; Foulkes 2010).

The issue of defining the relationship between a linguistic form and its associated social meaning (i.e. indexicality) is one that has garnered a significant amount of attention in the recent sociolinguistics literature (e.g. Eckert 2008, 2012). These discussions have centred primarily on the difficulty of ascribing a single and stable meaning to a given variant. Instead, scholars have argued that variants are ideologically linked to a range of related potential social meanings, any one of which could be made relevant in the context of interaction (e.g. Podesva 2007). Which of these potential meanings ultimately becomes activated is a product of both a speaker's stylistic practice (the use, for example, of coordinated indexical cues) and a listener's interpretation of the speaker's behaviour. In other words, because of the inherent 'indexical mutability' of language (Eckert 2012:94), social meaning is not viewed simply as a property of the stylistic moves a speaker makes. It crucially also relies on listener uptake. And it is here that stereotypes play a potentially pivotal role.

A case in point can be found in Campbell-Kibler's (2008) discussion of listeners' evaluative reactions to the (ING) variable (or the alternation between apical and dorsal realisations of the progressive -ing suffix in English) in the speech of Elizabeth, a speaker from California. Irrespective of Elizabeth's realisation of (ING), Campbell-Kibler found that all of her listeners perceived Elizabeth as a 'dynamic' and 'energetic' person. They differed, however, in their evaluations of this dynamism, with some listeners evaluating it positively and others negatively. Interestingly, this divide between positive versus negative evaluations of Elizabeth overall had an impact on listeners' interpretations of Elizabeth's use of the [in] variant: for those listeners who evaluated Elizabeth positively, her use of [in] evoked a stance of compassion. In contrast, for those listeners who evaluated Elizabeth negatively, [In] evoked a stance of condescension. Campbell-Kibler interprets these findings by arguing that both groups of listeners are reacting to [In]'s ability to index situational informality. This informality, however, is interpreted differently across listeners, such that those listeners who are already predisposed to dislike Elizabeth interpret her informality as condescending whereas those who are predisposed to like her interpret it as compassionate. The social meaning of [In] in Elizabeth's speech is therefore contextually dependent, and only emerges in relation to listeners' already existing beliefs and attitudes about the kind of person Elizabeth is. Put more simply, stereotypical reactions to Elizabeth as a person frame the listeners' evaluations of fine-grained sociolinguistic variation in her speech.

My aim in the discussion that follows is to pin down the influence that stereotypes can have on the perception of indexical language. I seek to determine 
which factors condition the variation we observe in sociolinguistic perception, and, in so doing, to understand the mechanism through which stereotypical attitudes and beliefs enable certain social meanings to emerge while simultaneously blocking others. I approach this topic through an investigation of how popular stereotypes of gender and sexuality in the UK impact upon listeners' evaluative reactions to specific patterns of phonetic variation in men's voices. I begin in the next section with a brief overview of the relevant literature on perceptions of sexuality in men's speech. I then go on to describe the experimental methodology employed in the current study, before turning to a discussion of my findings and their ramifications.

\section{PERCEIVING SEX U A LIT Y}

There is a popular belief that speech is a reliable marker of an individual's sexuality, and linguists have long been interested in identifying the particular acoustic features that cue such perceptions (see Munson \& Babel 2007 for a review). From the outset, a central concern of much of the research in this area has been to tease apart the potential linguistic correlates of perceived sexuality from those that cue other closely related social categories, like gender.

In his germinal sociophonetic study of the topic, for example, Gaudio (1994) elicited listeners' judgments of the perceived masculinity and the perceived gayness of eight male speakers, four of whom self-identified as 'gay' and four of whom did not. Gaudio found a strong negative correlation between listeners' judgments of the men's masculinity and their gayness, such that more masculine-sounding men were also heard as less gay-sounding (and vice versa). However, when he attempted to correlate these perceptions with prosodic differences in the men's speech (pitch range and pitch dynamism, in particular), Gaudio was unable to isolate the specific linguistic feature that cued perceptions of gender and sexuality for his listeners. Gaudio nevertheless reports a potentially meaningful statistical trend in his findings. All of the speakers in Gaudio's study were evaluated twice: once when reading a passage drawn from an accounting textbook (with little or no affect) and once when reading a monologue from a play (with a high level of affect). When comparing listener evaluations across these two speech contexts, Gaudio discovered a tendency for pitch range and pitch dynamism to influence listener judgments of speakers' gender and sexuality when they were reading the accounting passage but not when they were reading the dramatic one. In other words, higher levels of pitch variability in the men's voices served as indices of both femininity and gayness so long as the context of the passage was neutral with respect to affect. The lack of a significant linguistic effect for the dramatic passage leads Gaudio to argue that 'once men's speech is marked as 'dramatic' ... intonational variability plays a reduced role (or a different one, or none at all) in listeners' perceptions' (1994:50). 
A similar context effect was found in Smyth, Jacobs, \& Rogers (2003). In their study, listeners rated the perceived gender and sexuality of twenty-five men in three different situations: reading a scientific passage, reading a dramatic passage, and engaged in spontaneous conversation. Overall, Smyth and colleagues report a significantly greater proportion of gay- and feminine-sounding judgments for the scientific passage than for either the dramatic passage or the spontaneous conversation. Smyth and colleagues interpret this finding as evidence of a stereotypical association between gay men and 'formality' or 'prestige', such that men speaking in more formal contexts are more likely to be perceived as feminine/ gay than when they are speaking in more informal contexts. Smyth and colleagues, however, caution that while this pattern exists among the speakers as a group, there also exist differences among the individual men tested such that what listeners perceive as 'gay' or 'effeminate' in one man's voice does not necessarily get perceived in the same way in another's.

Subsequent studies have also found speaker effects of the kind mentioned by Smyth and colleagues (2003), where gayness and/or femininity are perceived in one voice but not in another. An earlier study of mine (Levon 2007), for example, used digitally manipulated speech stimuli to test perceptual reactions to variation in pitch range and sibilant duration. Two speakers' voices were tested: one that a pretest group labelled as sounding 'gay', the other that they labelled as sounding 'straight'. I found that narrowing the gay-sounding speaker's pitch range and shortening his sibilant durations caused listeners to judge the speaker as more 'masculine' and less 'gay'. This effect, however, was not replicated in the other direction: widening the straight-sounding speaker's pitch range and/or lengthening his sibilant durations had no impact on listeners' evaluations of the speaker's gender or sexuality. I interpreted this finding as indicating that there must be some phonetic property of the straight-sounding man's voice that effectively blocks the indexical properties of wider pitch range and longer sibilant durations.

To summarise, all of the studies discussed so far have discovered an interaction between perceptions of sexuality and the simultaneous perception of other salient cues in the speech signal, be they social (such as perceptions of gender), situational (such as perceptions of formality), or individual (such as variation across speakers). Yet because of the way these studies were designed, the researchers were unable to explore these interactions further. In contrast, a number of studies have set out explicitly to investigate the intersection of perceptions of sexuality and the perception of other categories and traits. Munson, McDonald, DeBoe, \& White (2006) examined the relationship between perceived sexuality and two additional factors: perceived speaker clarity and perceived speaker height. For men's voices, Munson and colleagues found a strong positive correlation between perceived gayness and perceived clarity, such that gayer-sounding voices were also perceived as sounding clearer. A regression analysis of these results revealed that approximately $50 \%$ of the variation in listener ratings of sexuality could be accounted for by judgments of clarity. An additional $16 \%$ to $19 \%$ of the variance was accounted for by 
specific linguistic cues, including first and second formant frequencies and the spectral skew of /s/. What these findings mean is that global perceptions of speaker clarity were more than twice as important as any specific linguistic feature in predicting listener judgments of men's sexuality. Though vowel formants and /s/-skewness played an additional role, Munson and colleagues' listeners appear to base their perceptions of sexuality in large part on a stereotypical association between gayness and clear speech. ${ }^{1}$

Campbell-Kibler (2011) provides additional evidence that listeners rely on stereotypical links between categories when arriving at judgments of a speaker's sexuality. In that study, Campbell-Kibler set out to test the intersecting percepts of gender, sexuality, and competence (operationalized as the traits 'smart' and 'knowledgeable') and their relationship to mean pitch, /s/-fronting, and (ING). She found that while in general there existed a significant positive correlation between judgments of masculinity and judgments of competence, such that more masculinesounding men also sounded more competent, that relationship broke down in two cases. The first involved those listeners who when hearing a man with a backed /s/ judged him as sounding 'straight'. For these listeners, masculinity and competence were not aligned, and speakers were judged as sounding masculine without necessarily sounding competent. The other situation in which the correlation broke down involved those listeners who when hearing a man with fronted /s/ and who used the velar -ing variant judged him as sounding 'gay'. In this case, listeners evaluated the man as sounding very competent even though he was not judged as sounding masculine. To account for these findings, Campbell-Kibler argues that the relevant listeners in her study are essentially basing their judgments on stored stereotypical representations of known types of men-the masculine, uneducated straight man and the effeminate, educated gay man respectively. In doing so, these listeners effectively disregard the more general correlation between perceived masculinity and perceived competence and instead rely on their stereotypes alone.

Lastly, a recent study of perceptions of sexuality in Copenhagen by Pharao, Maegaard, Møller, \& Kristiansen (2014) has uncovered an analogous stereotype effect, though in this case perceptions of gayness are seemingly blocked by perceived ethnicity. In their work, Pharao and colleagues examine listeners' reactions to /s/-fronting in two Danish guises. The first is what they call a 'modern' guise, and essentially refers to a man speaking in a (white) urban Copenhagen accent. The second they call the 'street' guise, a perceptually salient variety of Danish that is associated with Copenhagen's 'immigrant' population and with a so-called 'gangster' lifestyle. Pharao and colleagues find that /s/-fronting acts as a salient cue of gayness in the modern guise, but shows no such association in the street guise. In other words, listeners appear unwilling to label a 'street' speaker as gay-sounding even when /s/-fronting is present. Pharao and colleagues interpret this finding as indicating that /s/-fronting somehow loses its indexical link to gayness in the context of the 'street' accent. 
Taken together, the studies summarised here highlight the contingent nature of perceived sexuality. They demonstrate that while particular linguistic features may index gayness for certain listeners in some contexts, the relationship between language and a perceived social category is by no means fixed or stable. Rather, the extent to which a linguistic form cues perceived sexuality depends on the other social categories or traits that listeners also perceive and on the degree to which listeners believe these various categories and traits to be compatible. What this means is that research on perceptions of sexuality needs to move beyond developing a catalogue of sexuality-linked features since this does not reflect the reality of how social meaning is perceived. Instead, we must focus on uncovering the mechanism through which certain features come to take on sexuality-linked meanings in specific social and linguistic contexts and so uncover the ways in which the perception of sexuality is inter-dependent on the perception of other social constructs.

In the remainder of this article, I propose a two-pronged method for doing this. The method is based on ideas developed in the field of person perception within social psychology, and particularly research that has demonstrated the central role of STEREOTYPES in shaping how listeners construe social meaning in context (e.g. Macrae \& Bodenhausen 2001; Greenwald, Banaji, Rudman, Farnham, Nosek, \& Mellet 2002). Following this work, I define stereotypes as cognitive structures that link group concepts (e.g. man) with collections of both trait attributes (e.g. athletic, domineering) and roles (e.g. father). ${ }^{2}$ In other words, stereotypes are a form of associative social knowledge that serve to encode popular ideologies about social groups by linking the perceptual activation of a group concept with the activation of relevant trait attributes and roles. According to this formulation, the activation process is bi-directional in nature (such that a group concept like man can activate a trait attribute like athletic and vice versa) and is subject to spreading (such that athletic can activate domineering by virtue of the two attributes being within the same stereotype network). The theory also maintains that associations among stereotype components (i.e. between group concepts and linked attributes as well as among attributes themselves) can be of varying strength, such that a group concept can activate certain linked attributes and roles more strongly than it activates others. In short then, current understandings of the cognitive structure of stereotypes maintain that (a) they serve to facilitate the activation of linked attributes, but that (b) they do so to varying degrees depending on the strength of the concept-attribute link.

The experimental method that I describe in this article is designed to apply both of these insights to the study of linguistic perceptions of sexuality. First, paralleling the recent work by Campbell-Kibler (2011) and Pharao and colleagues (2014), I examine listeners' perceptions of different combinations of indexical linguistic features, including both those that are stereotypically compatible with gayness (e.g. features that potentially signal 'femininity') and those that I hypothesise are not (e.g. features that potentially signal 'working-class'). This aspect of the design allows me to investigate how correlations between language and perceived 
sexuality are affected by popular stereotypes of gay men. My prediction is that stereotypes will serve to block the simultaneous perception of normatively incompatible percepts, such that listeners who are presented with stimuli designed to signal both 'gay' and 'working-class,' for example, will only perceive one of these social attributes. This prediction is based both on the prior linguistic research cited above (e.g. Pharao et al. 2014) and is consistent with social psychological models of person perception (see e.g. Wyer 1998 on stereotype-inconsistent attribute inhibition).

The second prong of my analysis involves considering listeners' own attitudes towards gender and sexuality among men. Doing so makes it possible to pinpoint individual differences among listeners in terms of their relative endorsement of the stereotypes in question, and, in turn, to correlate these attitudinal findings with observed variation in listeners' perceptual reactions to language (Carahaly 2000). Here, the prediction is that individual attitudes will moderate any stereotypebased blocking effects, and may even directly influence whether particular linguistic features are perceived as cues for relevant social categories. Integrating an investigation of individual listener attitudes into the larger experimental protocol in this way provides the data necessary for examining the ways in which psychological, in addition to social and linguistic, factors together frame how listeners ultimately apprehend social meaning in context.

\section{E T H O D}

My focus in the present discussion is on stereotypes of male sexuality in Britain, and in particular on stereotypical beliefs regarding the tri-partite relationship between gender, sexuality, and social class. Of these three constructs, the relationship between gender and sexuality has received the most attention in the sociolinguistic literature. As described above, this work has found that perceptions of femininity and gayness in men are often highly correlated, such that men who are perceived as sounding more 'feminine' are normally also perceived as sounding more 'gay' (e.g. Gaudio 1994; Munson et al. 2006; Levon 2006, 2007; CampbellKibler 2011). In terms of a link between gender/sexuality and social class, research in history and sociology has argued that both effeminacy and gayness in men are normatively associated with higher social-class positions, particularly in Britain (Mosse 1985; Keogh, Dodds, \& Henderson 1994; Connell 1995, 2000). While little sociolinguistic research has focused specifically on the topic of sexuality and social class, there is nevertheless some support (both anecdotal and experimental) for the notion that listeners perceive gay-sounding speech as simultaneously sounding less working-class, and vice versa (see e.g. Lakoff 1975; CampbellKibler 2011; Mann 2012). My goal in what follows is to explore the extent to which these stereotypical links between categories are evident in listeners' perceptions. 
To achieve this goal, I examine listener judgments of three target variables, both in isolation and when combined with one another. Each of these variables has been identified in prior research as being indexically linked to one of the social categories in question:

- Mean pitch (GENDER) - as noted above, research in both sociolinguistics and phonetics has demonstrated that listeners regularly associate higher levels of mean fundamental frequency with effeminacy in men (e.g. Campbell-Kibler 2011; Drager 2011);

- Sibilance (SEXUALITY) — research has also shown that spectral properties of the voiceless sibilant /s/, including elevated levels of Centre of Gravity (CoG) and a more negative spectral skew, are positively correlated with listener perceptions of gayness in men (e.g. Munson et al. 2006; Campbell-Kibler 2011; Zimman 2013; Pharao et al. 2014);

- TH-fronting (SOCIAL CLASS) — work on social dialect variation in Britain has argued that labio-dental realisations of the voiceless inter-dental fricative (i.e. [f] for $/ \theta /$ ) are characteristic, and even stereotypical, of working-class speech in the UK (e.g. Kerswill 2003; Stuart-Smith \& Timmins 2006).

To test these features, I recorded three White British men from the southeast of England reading a short stimulus passage (see Appendix A). The men were in their mid- to late-twenties at the time of recording, were all postgraduate students at a major London university and had all been born and raised in the London metropolitan area. As such, all three men speak what can be described as Standard Southern British English. The stimulus passage itself recounts a mildly dramatic episode (someone falling down the stairs in a London underground station) and was designed to present listeners with a maximal number of tokens of both $/ \mathrm{s} /$ and $/ \theta /$ in as naturalistic a way as possible. In total, the forty-second passage contained twenty-seven instances of $/ \mathrm{s} /$ and fifteen instances of $/ \theta /$.

Test stimuli were constructed by manipulating multiple recordings of each speaker reading the passage. First, speakers each read the passage with all $/ \theta /$ tokens realised as $[\theta]$ and then again with them all realised as [f]. The labiodental realisations were then cut and pasted into the speakers' original recordings to create three FRONTED versions of the stimuli (i.e. one for each speaker). A similar procedure was followed for manipulating /s/ sibilance. In this case, all speakers read the passage with $/ \mathrm{s} /$ articulated as they normally would and were then coached to read the passage again with a more 'exaggerated' and 'sibilant' pronunciation. One of the speakers' 'exaggerated' articulations were then cut and pasted into the three original recordings to create sIBILANT versions of the stimuli. ${ }^{3}$ Finally, each of the speaker's mean pitch levels were shifted upward by $20 \mathrm{~Hz}$ using the pitch manipulation tool in Praat (cf. Levon 2006). Manipulations were executed on the pitch contour of each intonational phrase in the passage, resulting in SHIFTED versions of the stimuli. Table 1 presents the acoustic characteristics of the original, sibilant, and shifted stimuli for each of the speakers. No 
TABLE 1. Acoustic characteristics of original, shifted, and sibilant stimuli for all speakers.

\begin{tabular}{lcccc}
\hline \hline & Speaker: DH & Speaker: JW & Speaker: SG & Manipulated \\
\hline Mean /s/-CoG & $5779.91 \mathrm{~Hz}$ & $5871.97 \mathrm{~Hz}$ & $5508.5 \mathrm{~Hz}$ & $7446.15 \mathrm{~Hz}$ \\
Mean /s/-skewness & -0.74 & -0.79 & -0.89 & -1.42 \\
Mean F0 (grand mean) & $99.4 \mathrm{~Hz}$ & $100.6 \mathrm{~Hz}$ & $101.2 \mathrm{~Hz}$ & $119.9 \mathrm{~Hz}$ \\
\hline \hline
\end{tabular}

significant differences for the target variables were evident among the speakers in the original recordings, though the differences between the original and the manipulated stimuli are statistically significant for all three speakers.

The same manipulation process was repeated to create stimuli that combined multiple target variables (e.g. shifted mean pitch both with and without sibilant $/ \mathrm{s} /$ ). All of these manipulations resulted in the creation of three sets of eight experimental stimuli (one set per speaker), which together exhaust the possible combinations of the three target variables. ${ }^{4}$ These stimuli were presented online to 189 respondents, who were recruited from my own personal network and via calls for participation posted on various social networking sites. All respondents were native speakers of British English currently residing in the UK. Respondent age varied widely, though the majority of respondents were in their twenties and thirties (mean age: 30.1 ). Of the 189 respondents, 134 were women and fifty-five were men. 150 respondents identified as heterosexual and thirty-nine identified as lesbian, gay, or bisexual (LGB). ${ }^{5}$ Though detailed social class information was not collected from the respondent population, eighty-four respondents (44\%) listed occupations in the managerial, administrative, or professional sectors, forty-nine (26\%) listed occupations in the artistic, technical, or routine sectors, forty-five (24\%) identified themselves as students, and eleven $(6 \%)$ declared that they were unemployed. ${ }^{6}$

During the experiment, respondents heard a total of three recordings, one from each speaker. The selection of a recording for each speaker was fully randomised, as was the order of presentation of the three speakers. ${ }^{7}$ After hearing each recording, respondents rated the speaker on a series of eight six-point Likert scales (see Appendix B). These scales were designed to elicit listener judgments of various standard characteristics, such as speakers' perceived competence (intelligent/not intelligent, educated/not educated) and likeability (dependablelnot dependable, hardworking/ lazy, sincereldishonest, friendly/not friendly) as well as their perceived gender (masculine/not masculine) and sexuality (gay/not gay) (Scherer 1972; Gaudio 1994). ${ }^{8}$ After having rated all three speakers, respondents provided basic demographic information about themselves and completed a short Male Role Attitudes Survey (MRAS; Pleck, Sonenstein, \& Ku 1993, 1994). The MRAS (see Table 2) is a standard psychological instrument, designed to measure respondents' relative acceptance or rejection of stereotypical male gender roles. The MRAS asks listeners to indicate the extent of their agreement (on a five-point Likert scale) with eight normative statements that correspond to four aspects of male gender norms. The first of 
TABLE 2. Male role attitudes survey (adapted from Pleck et al. 1993, 1994).

( 1 = completely disagree; $3=$ neither agree nor disagree; $5=$ completely agree)

1. It is important for a man to be respected by others.

2. A man is responsible for earning a good income and providing for his family.

3. I admire a man who's sure of himself.

4. A man shouldn't talk about his problems.

5. It's important for a man to be physically tough even if he's not very big.

6. It bothers me if a man acts in a feminine manner.

7. I don't think men should have to do housework.

8. Men are always ready for sex.

these (questions 1-3) has to do with ideologies of status and the belief that masculinity entails occupying a socially dominant position. The second (questions 4-5) concerns notions of masculine toughness, both physical and emotional. The third (questions 6-7) is what Pleck and colleagues label 'anti-femininity', and reflects a dominant belief in the strict separation of sex roles. Finally, the fourth factor (question 8) involves a belief in a correlation between masculinity and promiscuity.

The MRAS was chosen as the primary attitudinal measure because my goal in this study is to examine the extent to which social stereotypes may cause the perception of a given characterological attribute (e.g. dependable) to be linked to the identification of another (e.g. masculine). Following the theory of stereotypical person perception outlined above, I hypothesise that what moderates this predicted perceptual linking is a listeners' relative endorsement of dominant gender stereotypes, which associate certain attributes with one another (e.g. dependable and masculine) while dissociating others (e.g. dependable and gay). In their presentation of the MRAS, Pleck and colleagues (1993:88) describe the scale as a measure of an individual's 'internalisation of cultural belief systems about masculinity and male gender ... including specific attitudes and dispositions about the various attributes that a man "should" have'. Rephrasing this in terms of the theory of stereotypes introduced above, by asking respondents to express their attitudes to male gender norms, the MRAS is able to access information about the strength with which the group concept man is linked to the different attributes considered (i.e. status, toughness, anti-femininity, and promiscuity), if at all. The MRAS is therefore preferred in the current research to other instruments, such as the Index of Homophobia (Ricketts \& Hudson 1998), that assess respondents' affective and behavioural reactions to particular social categories (e.g. I would feel uncomfortable working closely with a gay man) but do not directly address the issue of perceived stereotypical links between these categories and other relevant characteristics. ${ }^{9}$

The MRAS was originally tested (Pleck et al. 1994) on a racially diverse sample of 1,880 never-married adolescent American men from across the contiguous United States (respondents were between fifteen to nineteen years old at the time 
of testing and the sample population was 36\% 'Black', 21\% 'Hispanic', $41 \%$ 'White', and 2\% 'Other'). The sample was further stratified by a range of sociodemographic and personal background variables, including educational attainment, religious activity, sexual activity, and family income. Overall, Pleck and colleagues found that higher (i.e more stereotype-endorsing) scores on the MRAS were associated with being younger, having less educational attainment, more frequent church attendance, being sexually active, and identifying as 'Black'. They also found that MRAS scores are highly correlated with both homophobia and socalled 'male-problem behaviour', including substance abuse, crime, and sexual violence. Finally, Pleck and colleagues demonstrate the discriminant validity of the MRAS to identify attitudes towards masculine stereotypes specifically, to the exclusion of attitudes towards gender stereotypes more broadly.

My sample of 189 British respondents (both women and men) treated the MRAS as multidimensional. Factor analysis indicates the presence of two factors in listener responses to the scale: one corresponding to status (questions 1-3), physical toughness (question 5), anti-femininity (questions 6-7), and promiscuity (question 8), and another corresponding to emotional toughness (question 4). This second factor is relatively weak, associated with an eigenvalue of 1.02 and accounting for only $12.6 \%$ of the variance (as compared to an eigenvalue of 2.79 and $35 \%$ of the variance explained by the first factor). Moreover, overall reliability of the scale improves from an alpha score of 0.72 when all eight questions are considered to one of 0.76 when question 4 is removed. I therefore decided to exclude question 4 from calculations of individual average MRAS scores, and proceed with a modified scale that includes only those seven questions that all load onto a single factor. After modifying the MRAS in this way, the average score among respondents in my sample is 2.67 (where $1=$ completely disagree with the stereotype and $5=$ completely agree), with a standard deviation of 0.61 and a range of values spanning from 1.14 to 4.87 . On the whole, I find that higher modified MRAS scores are associated with younger $(\beta=-0.189, p<0.000)$, male $(\beta=0.202, p<0.000)$, and heterosexual ( $\beta=0.123, p=0.024)$ respondents, though there does exist significant variability across all of these categories. In the analyses that follow, I examine the extent to which this modified MRAS score along with listener sex, sexuality, age, and occupation predict the perceptual evaluations of the three linguistic variables considered.

\section{F I N D I N G S}

Listeners' ratings on the eight evaluation scales were subjected to linear mixedeffects regression models in R. Preliminary factor analysis (see Table 3) allowed for the reduction of these eight scales to three dependent variables for testing: perceived competence (comprised of the 'educated' and 'intelligent' scales), likeability (comprised of the 'dependable', 'lazy/hardworking', 'dishonest/sincere', and 'friendly' scales), and gender/sexuality (comprised of the 'masculine' and 'gay' 
TABLE 3. Factor loading and communalities of eight perceptual evaluation scales (Method: Principal components with varimax rotation).

\begin{tabular}{lcccc}
\hline \hline & 'Likeability' & 'Gender/sexuality' & 'Competence' & Communalities \\
\hline Intelligent & .299 & .034 & .861 & .832 \\
Dependable & .751 & .156 & .246 & .649 \\
Hardworking & .737 & -.006 & .126 & .559 \\
Masculine & .062 & .927 & .002 & .863 \\
Sincere & .779 & -.009 & .149 & .629 \\
Not Gay & .038 & .918 & -.075 & .850 \\
Friendly & .720 & .035 & .048 & .523 \\
Educated & .104 & -.109 & .905 & .842 \\
Eigenvalue & 2.87 & 1.79 & 1.09 & \\
\% Variance & 35.8 & 22.4 & 13.6 & \\
Cumulative $\%$ & 35.8 & 58.2 & 71.8 & \\
\hline \hline
\end{tabular}

scales). Regression models for each of these dependent variables were stepped down from full models that included the three manipulated variables, modified MRAS score, listener sex, listener sexuality, listener age, listener occupation, and all interactions. Speaker and listener were included as random effects. I discuss the experimental results for each of the three dependent percepts in turn, before going on to consider the ramifications of these findings. Model comparisons indicate that both the speaker and listener categories contribute to goodness of model fit. Thus while I do not discuss them in detail here, I report results from models that include speaker and listener as random effects.

\section{Perceiving competence}

The first analysis we consider is of listener evaluations of perceived competence. Prior research leads us to predict that a negative correlation would obtain between perceived competence and at least two of the three linguistic features under consideration. Campbell-Kibler (2011), for example, found a robust association between perceived competence and perceived masculinity in her study of listeners' subjective evaluations of men's voices in the US. If, as I suggest, mean pitch is saliently linked to perceived gender in men, we would therefore expect elevated mean pitch to be linked to a decrease in perceived competence. Similarly, much work on perceptions of dialect variation in the UK has found that features associated with working-class speech score poorly on scales related to competence (e.g. Edwards 1999; Coupland \& Bishop 2007). I would therefore predict that TH-fronting, which I take to be a potential cue of working-class speech, would also be negatively correlated with perceived competence. Finally, predictions with respect to the relationship between sibilance and perceived competence are somewhat less clear given the variety of both positive and negative correlations between 
TABLE 4. Linear mixed-model regression results for perceived competence.

\begin{tabular}{lrcrc}
\hline \hline Fixed effects & Estimate & Std. error & $t$ value & $p$ (MCMC) \\
\hline (Intercept) & 2.708 & 0.260 & 10.433 & 0.000 \\
Pitch (higher) & 0.541 & 0.235 & 2.298 & 0.022 \\
Sibilant (yes) & 0.106 & 0.203 & 0.522 & 0.602 \\
Pitch:Sibilant & -0.599 & 0.274 & 2.045 & 0.042
\end{tabular}

Total N: 567. Random effects: Listener (189); Speaker (3). Log likelihood $=-368.1$

competence and gayness that have been reported in the literature (e.g. CampbellKibler 2011).

Results for listener perceptions of competence are presented in Table 4. There, we find a significant main effect of pitch on perceived competence $(p=0.022)$, such that guises with higher mean pitch are judged as significantly less competent than those with lower mean pitch (on the competence scale, $1=$ most competent and $6=$ least competent). This result is in keeping with predictions for this feature. When we consider the actual scores across the respondent population, we find that the average rating for guises with lower pitch levels is 2.71 , while the average rating for guises with elevated pitch levels is 3.25 . In other words, shifting mean pitch upwards results in a decrease in average competence ratings of over half a point. Perceived competence is not significantly predicted by any of the external variables (sex, sexuality, age, occupation, or MRAS) nor is the association between pitch and perceived competence significantly conditioned by an interaction with any of these factors. What this means is that the link between elevated mean pitch levels and decreased levels of perceived competence is a percept that is shared by all respondents in the sample, regardless of individual attitudes or social group memberships.

The relationship between pitch and perceived competence is, however, constrained by a linguistic factor: the presence or absence of sibilance in the stimuli. In Table 4, we see that there is a significant interaction between pitch and sibilance $(p=0.042)$. The effect of this interaction is to neutralise the negative correlation between mean pitch and perceived competence when sibilance is present. In other words, higher mean pitch levels only serve to signal decreased competence when sibilance is absent. When sibilance is present, raising the mean pitch level has no effect on listener judgments of speaker competence. It is difficult to interpret this interaction based solely on the analysis of perceived competence. It could be the case, for example, that the presence of sibilance serves to signal some other percept whose activation interacts with the perception of competence, in effect inhibiting a downgrading of competence that is otherwise cued by elevated pitch. Or, it could be the case that listeners' attention is drawn away from pitch when sibilance is present for purely linguistic reasons (i.e. because of sibilance's psycho-acoustic salience; see e.g. Preston 2010). In order to select between these possible interpretations, 
TABLE 5. Linear mixed-model regression results for perceived gender/sexuality.

\begin{tabular}{lrcrc}
\hline \hline Fixed effects & Estimate & Std. error & $t$ value & $p$ (MCMC) \\
\hline (Intercept) & 4.065 & 0.759 & 5.350 & 0.000 \\
Pitch (higher) & -1.716 & 0.761 & -2.253 & 0.025 \\
Sibilant (yes) & -1.079 & 0.710 & -1.520 & 0.130 \\
Modified MRAS & -0.465 & 0.217 & -2.139 & 0.033 \\
Pitch:Sibilant & 2.046 & 1.000 & 2.046 & 0.042 \\
Pitch:MRAS & 0.799 & 0.281 & 2.844 & 0.005 \\
Sibilant:MRAS & 0.528 & 0.260 & 2.029 & 0.044 \\
Pitch:Sibilant:MRAS & -0.911 & 0.369 & -2.470 & 0.014
\end{tabular}

Total N: 567. Random effects: Listener (189); Speaker (3). Log likelihood $=-367.72$

we need to examine the behaviour of sibilance elsewhere in the dataset. For the moment, suffice it to say that sibilance blocks an otherwise regular association between elevated mean pitch and a perception of decreased competence.

\section{Perceiving gender/sexuality}

A second regression analysis examines listener evaluations on the gender/sexuality component (Table 5). The gender and sexuality scales are examined together due to their strong correlation with one another and the lack of any evidence of divergent validity of these scales among the listener population (as demonstrated in Table 3). ${ }^{10}$ My initial prediction is that both pitch and sibilance will be saliently linked to perceptions of gender/sexuality based on the prior research described above. While I am aware of no previous work that has examined the influence of TH-fronting on perceptions of gender/sexuality, I suggest that a salient association between $\mathrm{TH}$-fronting and working-class speech could lead to decreased perceptions of 'gayness' and increased perceptions of 'masculinity' given popular stereotypes of working-class men as normatively masculine and heterosexual.

In Table 5, we see that perceived gender/sexuality is predicted by a complex interaction involving mean pitch, sibilance, and modified MRAS score. For ease of interpretation, this interaction is depicted graphically in Figure 1. Figure 1 is a scatterplot that displays listeners evaluations of perceived gender/sexuality on the y-axis (where higher scores indicate a speaker sounds more 'gay' and less 'masculine') and individual MRAS scores on the $\mathrm{x}$-axis (where higher MRAS indicates more stereotype endorsing). In addition, four regression lines are plotted in Figure 1. Each of these lines corresponds to one of four possible combinations of pitch and sibilance in the stimuli (i.e. shifted versus nonshifted mean pitch crosstabulated with increased vs. unmodified sibilance). Regression lines for nonshifted mean pitch are in black, while those for shifted mean pitch are in grey. Likewise, lines for unmodified sibilance are solid, while those for increased sibilance are dashed. ${ }^{11}$ 


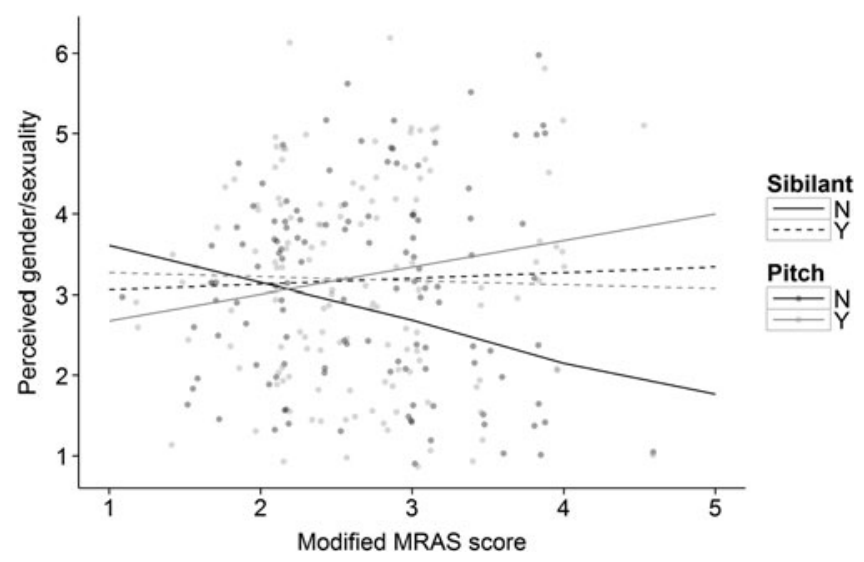

FIGURE 1. Plot of the interaction of pitch, sibilance, and modified MRAS score in predicting percieved gender/sexuality.

The three-way interaction depicted in Figure 1 reveals two important patterns. The first is that the extent of listeners' endorsement of normative masculine stereotypes mediates the observed association of mean pitch and/or sibilance with perceived gender/sexuality. On the left side of Figure 1, we see that the trend lines for ratings of gender/sexuality for listeners with lower MRAS scores are similar across all four stimuli. Post-hoc tests confirm this and indicate that neither pitch nor sibilance has an effect on perceived gender/sexuality for MRAS scores below 2.5 (for pitch, $p=0.85$; for sibilance, $p=0.38$ ). As we move rightward in Figure 1, however, we see that the regression lines associated with shifted nonsibilant guises (the solid grey line) and with sibilant nonshifted guises (the dashed black line) begin to diverge from the line associated with nonshifted nonsibilant guises (the solid black line). This divergence indicates that listeners with higher MRAS scores associate mean pitch and sibilance with perceived gender/sexuality, and rate guises with elevated mean pitch and increased sibilance as significantly 'gayer' and less 'masculine'. Post-hoc tests again confirm this pattern: listeners with MRAS scores between 2.5 and 3.5 show a trend towards associating higher mean pitch and increased sibilance with 'gayness' and decreased 'masculinity' (for pitch, $p=0.09$; for sibilance, $p=0.11$ ). This trend becomes highly significant among listeners with MRAS scores above 3.5 (for pitch, $p=0.003$; for sibilance, $p=0.009) .{ }^{12}$

This pattern is important because it demonstrates that individual attitudes constrain the meanings that listeners associate with linguistic features. For those listeners who subscribe to a normative conceptualization of male gender roles, both pitch and sibilance act as salient cues of gender/sexuality in men's voices. Those listeners, in contrast, who do not endorse stereotypical gender norms show no such association. This variation according to MRAS score provides further empirical 
support for the notion that the indexical values of linguistic features are mutable (Eckert 2012) and that the activation of social meaning depends on a range of conditioning factors. While much prior research has focused on the different social and contextual parameters that structure indexical mutability, the analysis presented here illustrates that listener attitudes play a central role, such that a listener's affective beliefs about masculinity, for example, influence whether or not a particular feature is perceived as sounding 'gay'. In other words, these results demonstrate how individual attitudinal differences can constrain the social meanings that are perceived, in much the same way that listeners' prior experiences and the context of interaction can (Preston 2010). Moreover, this finding may also help to shed light on the results of previous research examining a predicted link between pitch/sibilance and perceived gender/sexuality. As noted above, numerous studies have examined these features and their results have been uneven, with some scholars finding significant effects and others finding none whatsoever (e.g. Gaudio 1994; Munson 2007; Campbell-Kibler 2011). The current discussion provides a potential account for this unevenness by demonstrating the role that stereotype endorsement plays in mediating the establishment of such an indexical link.

Aside from the interaction with MRAS, no other external factor was selected as significant in predicting judgments of gender/sexuality. It is therefore not the case that MRAS scores are simply capturing perceptual variability that is governed by listener sex, sexuality, age, or occupation. While it is true that, overall, MRAS scores are differentially distributed across these categories, separate analyses confirm the presence of a parallel MRAS effect within all subgroups. For example, though no LGB respondent scored above 4 on the MRAS scale, a significant interaction between pitch/sibilance and MRAS scores in predicting perceived gender/sexuality is nevertheless present among LBG listeners ( $p=0.018)$. In other words, stereotype endorsement significantly conditions listeners' perceptual evaluations of gender and sexuality regardless of group membership (and despite significant differences in group-wide attitudes overall).

The second pattern revealed by the three-way interaction between pitch, sibilance, and MRAS score in Figure 1 relates to the nonadditivity of the pitch and sibilant effects themselves. We have already seen how both pitch and sibilance in isolation affect perceptions of gender/sexuality among listeners with higher MRAS scores. When we examine the trend line in Figure 1 for listener responses to stimuli with both elevated mean pitch and increased sibilance (the dashed grey line), we find that its slope tracks the slopes of the lines for stimuli with either elevated mean pitch or increased sibilance only. Pairwise comparisons among the four types of stimuli confirm this pattern and reveal that there is no significant difference in listener evaluations of perceived gender/sexuality among the shifted only, sibilant only, and shifted and sibilant stimuli. In other words, for those listeners who associate pitch/sibilance with gender/sexuality, the combination of elevated mean pitch and increased sibilance does not lead to an increase in a speaker's perceived nonmasculinity/gayness beyond what is achieved by either of the variables alone. 
Rather, guises that are both shifted and sibilant are perceived to be equally as nonmasculine/gay-sounding as those guises that are either only shifted $(p=0.281)$ or only sibilant $(p=0.310) .{ }^{13}$ This finding contrasts with previous work on perceptions of sexuality that has found additive effects to be the norm (e.g. Levon 2007; Campbell-Kibler 2011).

The apparent nonadditivity of pitch and sibilance on the gender/sexuality scale is reminiscent of the interaction identified previously between pitch and sibilance on the competence scale. There, we saw that an otherwise robust association between elevated mean pitch and decreased perceived competence was neutralised when sibilance was present. When discussing this effect on the perceived competence scale, I noted that the interaction could be due either to the activation by sibilance of some additional percept, which serves to block the indexical value of pitch, or to the relative linguistic prominence of sibilance, which causes listeners to disregard pitch. In this instance, however, the possibility of one percept 'blocking' another does not arise, since both mean pitch and sibilance are indexically linked to the same percept (i.e. perceived gender/sexuality). The nonadditivity of pitch and sibilance on the gender/sexuality scale can therefore not be attributed to a stereotype blocking effect and an explanation must be located elsewhere. I return to this point in the discussion below.

\section{Perceiving likeability}

The final regression analysis examines listener judgments on the likeability component (Table 6). Recall that this component is composed of judgments of how 'dependable', 'hardworking', 'sincere', and 'friendly' a speaker is. The likeability component therefore corresponds to the solidarity or social attractiveness dimension of listeners' perceptual evaluations (e.g. Coupland \& Bishop 2007). Given this, we predict a positive correlation between TH-fronting and judgments of 'likeability' based on the popular association of working-class speech and social attractiveness. In terms of pitch and sibilance, though there are no direct predictions for the effect of these variables on evaluations of likeability, I propose that the association of pitch and sibilance with gender/sexuality (at least for some listeners) could lead to a negative correlation between these features and perceived likeability.

TABLE 6. Linear mixed-model regression for perceived likeability.

\begin{tabular}{lrcrc}
\hline \hline Fixed effects & Estimate & Std. error & $t$ value & $p$ (MCMC) \\
\hline (Intercept) & 3.015 & 0.150 & 20.092 & 0.000 \\
Sibilant (yes) & -0.367 & 0.202 & -1.872 & 0.117 \\
TH-fronting (yes) & -0.495 & 0.203 & -2.439 & 0.015 \\
Sibilant:TH-fronting & 0.757 & 0.277 & 2.735 & 0.007
\end{tabular}

Total N: 567. Random effects: Listener (189); Speaker (3). Log likelihood $=-301.94$ 
In Table 6, we find that there is a significant effect of TH-fronting on perceived likeability such that fronted guises are rated on average nearly half a point more 'likeable' than nonfronted guises ( $p=0.015$; for the likeability scale, $1=$ very likeable and $6=$ not at all likeable). As noted above, this main effect is to be expected if TH-fronting is indeed a salient marker of working-class speech in the UK (e.g. Kerswill 2003). In the current sample, listeners gave an average rating of 3.01 on the 'likeability' scale to guises without TH-fronting, and an average rating of 2.52 for those with TH-fronting. This half-point difference indicates a boost to perceptions of likeability for TH-fronted guises. It is possible to interpret this result as another example of the well-documented pattern of vernacular features enhancing listener perceptions of a speaker's social attractiveness (e.g. Edwards 1999). The fronting effect is, however, conditioned by a significant interaction with sibilance $(p=0.007)$. The interaction between TH-fronting and sibilance indicates that when sibilance is present, fronting has no effect on perceived likeability. In other words, listeners rate fronted sibilant guises as being as 'likeable' (or 'unlikeable') as nonfronted sibilant guises. This interaction, like the effect of fronting more generally, applies to all listeners, regardless of their sex, sexuality, age, occupation, or MRAS score.

There are a number of potential interpretations of this pattern. The first is that the observed interaction between sibilance and TH-fronting is an example of what social psychologists have termed STEREOTYPE INCONSISTENT ATTRIBUTE INHIBITION (Macrae \& Bodenhausen 2001; Wigboldus, Dijksterhuis, \& van Knippenberg 2003). Recall that a salient association was identified between increased sibilance and perceived nonmasculinity/gayness. The interaction between sibilance and $\mathrm{TH}-$ fronting on perceived likeability could thus be potentially interpreted as an unwillingness on the part of listeners to allow voices that they perceive as nonmasculine/ gay to be simultaneously perceived as more likeable. In other words, it could be the case that the percept of gender/sexuality (cued by sibilance) inhibits the percept of likeability (otherwise cued by fronting) among listeners because of some stereotype-driven perceived incompatibility between the two. This interpretation would be consistent with a great deal of research in social psychology that has demonstrated that stereotypes (conceptualised as combinations of linked attributes) serve to block the perception of stereotype-inconsistent traits (i.e. those attributes that fall outside of the linked network).

There is, however, no direct evidence for such an inhibition effect in the data. If perceived likeability were indeed being 'blocked' by perceived gender/sexuality, we would anticipate this effect to be further constrained by listener attitudes towards masculinity. That is to say that we would expect to find an additional significant interaction with MRAS scores, such that those listeners who endorse normative stereotypes of masculinity would display the blocking effect while those who do not endorse the stereotype would not. This is particularly true given that sibilance was only shown to cue perceived gender/sexuality for listeners with higher MRAS scores (see Table 5). Yet the MRAS index plays no role in the 
observed effect; TH-fronting is inoperative in the presence of sibilance for all listeners equally, regardless of whether they endorse masculine stereotypes or not. It therefore seems inappropriate to argue for a stereotype-driven blocking effect when not all listeners associate sibilance with perceived gender/sexuality, or even all report endorsing the stereotype that is presumably responsible.

Nevertheless, it could be that the MRAS is not a sensitive enough measure to uncover the attitudes concerned (e.g. Devine 1989), and that some sort of response bias is responsible for the mismatch between results on the perceived gender/sexuality scale (where MRAS plays a significant role) and results on the perceived likeability scale (where it does not). What I mean is that the MRAS scale may not be capturing attitudes to masculine stereotypes per se, but rather a differential willingness on the part of listeners to explicitly label a male speaker as 'less masculine' and 'gayer'. This could mean that all listeners associate sibilance with gender/sexuality, and that only those listeners who endorse normative masculine stereotypes are willing to express as much in the type of overt experimental task used here. If this were the case, then the interaction between sibilance and TH-fronting could be taken to reveal an implicit ideological incompatibility between 'nonmasculinity'/'gayness' and 'likeability' that is shared by all listeners, even in the absence of an overt MRAS effect. While this interpretation is plausible, I would argue that it relies on too many currently unjustified assumptions about the listener population to be retained. Additional research using more implicit attitudinal measures (e.g. Fazio, Sanbonmatsu, Powell, \& Kardes 1986; Greenwald, McGhee, \& Schwartz 1998; Campbell-Kibler 2012) would be required to substantiate such an account.

Based on the current data, I believe that a more robust interpretation of the interaction of sibilance and TH-fronting in conditioning perceived likeability is that the pattern observed is an example of contextual nonattention. As noted above, research in both psychology and linguistics has shown that listeners selectively attend to stimuli in the signal when perceiving and evaluating voices (e.g. Nosofsky 1986; Nusbaum \& Morin 1992; Pendry \& Macrae 1996; Macrae \& Bodenhausen 2001; Preston 2010). Selective attention of this sort does not imply 'blocking' of one cue by another, but rather that certain cues are more salient in particular environments leading to an attenuation of listeners' attention to other cues that may also be present. In other words, in cases of stereotype-inconsistent attribute inhibition, both of the relevant meanings are cognitively activated but the incompatibility between these meanings causes one of them to be inhibited. In cases of contextual nonattention, in contrast, the only meaning that is activated is the one linked to the more salient linguistic feature. Thus while in both cases only one feature and its associated meaning end up being perceived, the underlying cognitive mechanism that leads to that perception is distinct. Applying a contextual nonattention interpretation to the current example would mean that sibilance is more salient than TH-fronting (and its associated percept of likeability) causing listeners to disregard any effect that TH-fronting might otherwise have. Crucially, according to this scenario 
the determination of salience is not necessarily attitude-driven but results from external factors, including the formal properties of the target features themselves (Preston 2010, 2011). Building on this idea, I suggest that since /s/ sibilance is phonetically so much more prominent than TH-fronting, sibilance trumps fronting on psycho-acoustic grounds, leading listeners to pay attention only to sibilance at the expense of fronting. ${ }^{14}$

An analysis based on selective attention has the benefit of providing an account for the interaction between sibilance and TH-fronting on the perceived likeability scale without having to resort to claims regarding implicit or automatic attitudes. ${ }^{15}$ Furthermore, such an analysis can also model the two other instances of interactions with sibilance described previously (i.e. between pitch and sibilance on perceived competence and between pitch and sibilance on perceived gender/sexuality). I propose that for all three of the percepts considered, the presence of sibilance draws attention away from the other linguistic variables in the stimuli. In addition, I suggest that sibilance does so because of a general processing constraint that, at least in the context of the current experimental task, encourages listeners to selectively attend to linguistically more prominent features in the speech signal. For the 'competence' and 'likeability' scales, this constraint causes listeners to effectively disregard pitch and TH-fronting (and their associated indexical meanings) when these features are combined with the perceptually more salient sibilance. For the 'gender/sexuality' scale, I would argue that the process is very much the same, with the only difference that sibilance itself can serve as a salient cue to perceived gender/sexuality for some listeners (hence the significant boost to relevant listeners' evaluations of the perceived nonmasculinity/gayness of shifted sibilant stimuli as compared to nonshifted nonsibilant stimuli). In all cases then, I propose that selective attention plays a central role in structuring listeners' perceptions of socioindexical meaning, even to the point of rendering certain variables contextually 'meaningless' when combined with linguistically more prominent others.

In short, an analysis based on selective attention is able to capture all of the empirical facts in the current dataset. It is, moreover, consistent with much research on person perception in psychology, which has demonstrated the importance of cognitive economy constraints in shaping how perceivers react to socially meaningful stimuli (Macrae \& Bodenhausen 2001; Devine \& Sharp 2007; see also Campbell-Kibler 2014 for a discussion of cognitive economy in sociolinguistics). Nevertheless, I concede that further evidence of the relevance of cognitive economy for the listeners in my sample is necessary. While beyond the scope of the current study, such evidence could be obtained via additional experimental tasks that manipulated listeners' cognitive load and/or more directly examined respondents' ability to discern relevant linguistic contrasts. In the absence of this additional evidence, I simply argue that an analysis based on selective attention provides the most parsimonious account of the observed interactions between sibilance and both pitch and TH-fronting. 
My goal in this article has been to examine the mechanism that underlies how listeners come to associate linguistic variation with perceived sexuality. Building on previous work in this area as well as on recent developments in sociolinguistics more broadly (e.g. Eckert 2012), I argue that we need to move beyond looking for static connections between variables and perceived social correlates and instead explore how relevant social meanings emerge for certain listeners in particular contexts. To that end, I examined listeners' reactions to the intersecting categories of sexuality, gender, and social class by eliciting responses to three category-relevant variables (sibilance, mean pitch, and TH-fronting respectively) both in isolation and in combination with one another. My hypothesis was that, when combined, these linguistic cues would interact with one another such that the social meaning potential of a feature associated with a particular social attribute (e.g. 'gay') would be blocked when the feature was paired with another whose social meaning is stereotypically incompatible (e.g. 'working-class'). I added to this a simultaneous examination of listener attitudes towards masculinity under a second hypothesis that levels of individual stereotype endorsement will have an effect on how socioindexical information is processed.

Of these two hypotheses, only the latter is directly supported by the results presented here. While 'competence' and 'likeability' are consistently signalled across the listener population by pitch and $\mathrm{TH}$-fronting respectively, the indexical relationship between pitch/sibilance and perceived gender/sexuality was shown to be MEDIATED by individual listener attitudes. For those listeners who endorse normative stereotypes of masculinity and male gender roles, pitch and sibilance serve as salient cues of 'nonmasculinity' and 'gayness'. For those, in contrast, who reject these stereotypes, pitch and sibilance have no such effect. This result provides positive evidence in support of the claim that listeners' individual beliefs impact on the types of social meanings they associate with variation.

My other hypothesis - that stereotypes block the emergent meanings of variables in particular contexts-is, however, not supported by the results. While blocking effects among linguistic features are identified for all three percepts, in none of these is there evidence that this effect is constrained by individual levels of stereotype endorsement. A case in point is the apparent 'blocking' of pitch by sibilance of perceived gender/sexuality, where both features are linked to the same perceptual category and so the issue of stereotype incompatibility does not arise. Even in those cases where a stereotype effect could potentially emerge (i.e. on the 'competence' and 'likeability' scales), sibilance is shown to neutralise the indexical potential of pitch and TH-fronting for all listeners irrespective of their attitudes. Given these empirical facts, I suggest that the observed interactions between linguistic features are not stereotype-driven but are rather grounded in a more general principle of cognitive economy that causes listeners to selectively attend to the most perceptually prominent variables in the stimuli. In making this proposal, I do not mean to 
suggest that listeners never attend to combinations of features or even that economic modes of perception are always the norm. Other research has shown that clusters of features can elicit both additive and alternative judgments from listeners (e.g. Levon 2007; Campbell-Kibler 2011). My argument is simply that this need not always be the case, and that sociocognitive processing constraints can moderate the amount of attention that listeners devote to perceiving a speech signal.

While I acknowledge that my arguments regarding selective attention require further external support, I nevertheless maintain that, when taken together, the findings of the current experiment have important ramifications for our understanding of how listeners perceive sexual, as well as other social, meanings. First and foremost, the results illustrate the LISTENER-DEPENDENT nature of sociolinguistic perception, such that a form/meaning relationship that exists for one listener does not necessary exist for another (Foulkes 2010). While this kind of cross-listener variability has long been noted in the literature, the analysis proposed here is able to account for it and to demonstrate the ways in which listeners' attitudes constrain the social meanings that are perceived. This is important from the perspective of language and sexuality research since it allows us to understand some of the inconsistencies of prior empirical findings, and serves as a kind of methodological blueprint for work in this area going forward.

From a conceptual point of view, the current analysis also provides further support for a general understanding of social meaning as an emergent property of language (Eckert 2012). The observed role of listener attitudes in mediating the relationship between a variable and a social meaning supports a conceptualisation of so-called variable 'under-specification', whereby linguistic forms are associated with a variety of potential meanings in a unified indexical field and where the activation of a given meaning is determined by the social contours of an interaction (Eckert 2008). As the analyses of combinations of features here shows, however, I would argue that social factors are not the only ones that play a role. Rather, the mechanism that governs the activation of social meaning also appears to be influenced by general cognitive constraints that, in certain contexts at least, encourage listeners to selectively attend only to certain features in a speech signal when making perceptual judgments. This addition to current models of social meaning is important because it highlights a potential operational difference between sociolinguistic PRODUCTION, where speakers have been shown to recruit a variety of variable forms to construct a nuanced presentation of self, and sociolinguistic PERCEPTION, where much of that nuance may be lost due to a more cognitively economical mode of processing. If, as I argue above, social meaning is by definition dependent on listener uptake, then this distinction between production and perception has serious implications for theories of linguistic indexicality.

By extension, the results of the current study also have important ramifications for questions traditionally viewed as being at the heart of the variationist enterprise, including those related to the distribution and progression of language change. A growing body of research over the past fifteen years had demonstrated that 
sociolinguistic changes can grow and diffuse as a result of speakers' strategically deploying variation to achieve specific social and interactional goals (Eckert 2000, 2008; Milroy 2004; Woolard 2008). Eckert (1996), for example, discusses how /æ/-backing before nasals is spreading among Chicana girls in Northern California in part because of the feature's local association with adulthood and sexual maturity. Understanding the social meanings listeners come to associate with variables is thus central to our ability to model how patterns of variation are propagated. And, as Silverstein (1979) notes, the necessary precursor to speakers' developing local meanings for features is their 'noticing' an association (whether real or imagined) between particular linguistic forms and certain kinds of speakers (see also Johnstone \& Kiesling 2008). My argument in this article is that the ability of individuals to notice such associations is itself constrained by both individual attitudinal and more general cognitive factors. The findings presented here thus serve to underscore the complexity of sociolinguistic perception - a complexity that I argue we must take seriously if we wish to provide a robust account of socially meaningful variation and change.

\section{A P PENDIX A : STIMULUS TEXT}

So last Thursday I was walking down the steps to the tube and there were these two guys walking up on the other side. Both of them were texting on their phones and joking with each other, and I guess one of them slipped or something 'cuz all of a sudden he starts falling backwards and throwing his arms in the air. And for like three seconds he was just sort of balanced there, and I thought, you know, he'd pull himself up. But then he tipped even further back and just started tumbling down the stairs and landed on the floor and his head smashed right on the tiles. For a second nothing happened, but then blood started streaming out of his head and it didn't look like he was breathing. And the guy's friend, rather than try to help or anything, just stood there and looked at him. I shouted at him to call an ambulance, and they came pretty soon. The guy turned out to be okay - he just had a nasty gash on the side of his head, but otherwise he was fine.

A P PEN DIX B: EVALUATION SCALES

$\begin{array}{llllllll}\text { Very intelligent } & \square & \square & \square & \square & \square & \square & \text { Not at all intelligent } \\ \text { Very dependable } & \square & \square & \square & \square & \square & \square & \text { Not at all dependable } \\ \text { Very lazy } & \square & \square & \square & \square & \square & \square & \text { Very hardworking } \\ \text { Very masculine } & \square & \square & \square & \square & \square & \square & \text { Not at all masculine } \\ \text { Very dishonest } & \square & \square & \square & \square & \square & \square & \text { Very sincere } \\ \text { Very gay } & \square & \square & \square & \square & \square & \square & \text { Not at all gay } \\ \text { Very friendly } & \square & \square & \square & \square & \square & \square & \text { Not at all friendly } \\ \text { Very educated } & \square & \square & \square & \square & \square & \square & \text { Not at all educated }\end{array}$




\section{EREZ LEVON}

\section{N O T E S}

*Special thanks to Kathryn Campbell-Kibler, Jenny Cheshire, Penny Eckert, Miriam Meyerhoff, Nicolai Pharao, Jane Stuart-Smith, Lal Zimman, two anonymous reviewers, and audience members at NWAV 41 at Indiana University in 2012 and ExAPP 2 at the University of Copenhagen in 2013 for their comments on earlier stages of this research. I would also like to express my gratitude to the three speakers for lending me their voices, and to the numerous colleagues who helped me to distribute the online experiment. All errors and shortcomings are, of course, my own.

${ }^{1}$ As Munson and colleagues note, this finding does not necessarily imply that there exists a causal relationship between perceived clarity and perceived sexuality or that speakers are consciously aware of such an association. Moreover, it is entirely possible that the link between clarity and sexuality is an indirect one and is mediated by some other perceived attribute (e.g. education).

${ }^{2}$ Stereotype components (i.e. concepts, attributes, and roles) are also standardly assumed to be associated, either directly or indirectly, with VALENCE CONCEPTS (i.e. positive or negative evaluations). There is some debate within the field as to whether these evaluations are themselves part of a stereotype or an additional sociocognitive structure that is associated with stereotyped social groups. This debate is beyond the scope of my discussion here and does not bear directly on my use of the theory.

${ }^{3}$ The speaker with the highest peak frequency in his 'exaggerated' pronunciation of /s/ was chosen for creating the sibilant tokens. A reviewer notes that pasting in a different speaker's sibilants could lead to a mismatch in terms of filter size for the other two speakers. This potential mismatch appears to have had no perceptual effect and was not remarked upon in the naturalness testing of the stimuli (see note 4).

${ }^{4}$ All eight guises were judged to sound 'natural' (i.e. not manipulated) by both myself and four linguist colleagues who were otherwise unrelated to the project.

${ }^{5}$ Though not a balanced listener sample in terms of gender and sexuality, the split of women versus men (roughly $70 \%$ versus $30 \%$ ) and LBG versus non-LGB (roughly $20 \%$ to $80 \%$ ) falls well within the parameters required for robust multivariate analysis (see Guy 1993).

${ }^{6}$ The different occupational sectors described here are based on the British Office for National Statistics' Socio-economic Classification schema (NS-SEC). Available at www.ons.gov.uk; accessed on November 21, 2013.

${ }^{7}$ Following previous research in this paradigm (e.g. Levon 2007; Campbell-Kibler 2011), listeners heard only one recording per speaker so as to eliminate the possibility that they would recognise the existence of multiple recordings of the same individual and so perhaps identify the objective of the experimental task. Because the linguistic manipulations of the stimuli were relatively minimal (between one and three variables per stimulus), all of the stimuli derived from the same person are obviously spoken by the same speaker. Since it is somewhat counterintuitive to ask listeners to rate the speakers of the different stimuli when the stimuli are all obviously spoken by the same individuals, a between-subjects methodology was employed.

${ }^{8}$ For gender and sexuality ratings, I use scales based on concept negation (e.g. gay/not gay) rather than semantic differentials (e.g. gay/straight) so as to avoid positing the existence of a continuum between 'gay' and 'straight' or 'masculine' and 'feminine' (or indeed to avoid suggesting that 'gay'/'straight' and 'masculine'/'feminine' are polar opposites of one another). Listeners were instead asked to rate the extent to which they believe the stimulus corresponds to their own conceptualisation of gayness or masculinity, with the acknowledged caveat that individual conceptualisations of gayness/masculinity may vary across listeners.

${ }^{9} \mathrm{~A}$ distinction between attitudes towards gender stereotypes and attitudes towards social categories is particularly important given the emergence of the so-called neoliberal gay subject (e.g. Duggan 2002; Seidman 2002), whose identity is marked solely in terms of sexual preference and not lack of adherence to gender norms, as the dominant model of gay male sexuality. Because of this, it is entirely possible for individuals today to maintain positive attitudes to gay men overall, while still fully endorsing normative masculine gender stereotypes. Since I hypothesise that it is the relative endorsement of gender stereotypes that moderates the extent to which listeners associate the perception of one attribute with another, it is important for me to access attitudes to stereotypes, as opposed to social categories, directly. 


\section{THE LINGUISTIC PERCEPTION OF SEXUALITY}

${ }^{10}$ In analysing these scales as a single percept, I am not making any a priori claims about the status of 'gender' and 'sexuality' as distinct social and theoretical constructs. I am simply following the empirical evidence, which indicates that listeners in the current study do not evaluate these scales differently with respect to the variables tested.

${ }^{11}$ For ease of presentation, trend lines in Figure 1 are based on model predicted values. Scatterplot smoothers plotted over the raw data reveal the same pattern as in Figure 1.

${ }^{12}$ Post-hoc testing further reveals that the apparent negative correlation in Figure 1 between MRAS score and perceived gender/sexuality for nonshifted nonsibilant guises (solid black line) is not significant $(t=-1.577 ; p=0.143)$. This finding indicates that level of stereotype endorsement has no effect on listener evaluations of gender/sexuality when both higher pitch and increased sibilance are absent.

${ }^{13}$ Note too that the average ratings for pitch and sibilance in isolation are nowhere near ceiling (i.e. a rating of 6). This indicates that, at least in theory, it would be possible to obtain a heightened evaluation of the perceived nonmasculinity/gayness for stimuli that are both shifted and sibilant.

${ }^{14} \mathrm{As}$ a reviewer notes, though sibilance is acoustically more prominent, TH-fronting involves a shift between phoneme categories and is thus potentially high in phonological salience. While this is certainly true, research on phoneme intelligibility in English has demonstrated that the distinction between [f] and $[\theta]$ is 'among the most difficult for listeners to hear and it seems likely that in most natural situations the differentiation depends more on verbal context and on visual observation of the talker's lips than it does on acoustic difference' (Miller \& Nicely 1955:347). Given that there was no visual accompaniment to speech in the current experiment and that the verbal context in the stimulus passage was sufficient to disambiguate the meaning of fronted tokens, I base my argument here on the notion that phonetic salience is what drives the contextual (non)salience effect (see also Yaeger-Dror 1993).

${ }^{15}$ I concede that the structure of the experiment itself may have caused the category 'gay' to be more fully activated than the category 'working-class' in the minds of listeners. While perceived gayness and perceived masculinity were both measured directly, perceived social class was only measured indirectly. It would therefore be useful to see if this result is replicated in a different experimental design where categories of gender and sexuality are not explicitly mentioned.

\section{R E F E R E N C E S}

Campbell-Kibler, Kathryn (2008). I'll be the judge of that: Diversity in social perceptions of (ING). Language in Society 37:637-59.

(2009). The nature of sociolinguistic perception. Language Variation and Change 21:135-56.

(2011). Intersecting variables and perceived sexual orientation in men. American Speech 86:52-

68.

(2012). The implicit association test and sociolinguistic meaning. Lingua 122:753-63.

(2014). Updating the sociolinguistic monitor: Toward a cognitively realistic model of meaningful sociolinguistic variation. In Anna Babel (ed.), Awareness and control in sociolinguistic research. Cambridge: Cambridge University Press, to appear.

Carahaly, Lynn (2000). Listener accuracy in identifying the sexual orientation of male and female speakers. Columbus: The Ohio State University, Department of Speech and Hearing Sciences M.A. thesis.

Connell, R. W. (1995). Masculinities. Cambridge: Polity.

(2000). The men and the boys. Cambridge: Polity.

Coupland, Nikolas, \& Hywel Bishop (2007). Ideologised values for British accents. Journal of Sociolinguistics 11:74-93.

Devine, Patricia (1989). Stereotypes and prejudice: Their automatic and controlled components. Journal of Personality and Social Psychology 56:5-18.

—, \& Lindsay Sharp (2007). Automaticity and control in stereotyping and prejudice. In Todd Nelson (ed.), Handbook of prejudice, stereotyping and discrimination, 61-87. New York: Psychology Press. 


\section{EREZ LEVON}

Drager, Katie (2011). Style and perceived sexuality. Paper presented at New Ways of Analysing Variation (NWAV) 40. Washington, DC: Georgetown University.

Duggan, Lisa (2002). The new homonormativity: The sexual politics of neoliberalism. In Russ Castronovo \& Dana Nelson (eds.), Materializing democracy: Toward a revitalized cultural politics, 175-94. Durham, NC: Duke University Press.

Eckert, Penelope (1996). Vowels and nail polish: The emergence of linguistic style in the preadolescent heterosexual marketplace. In Natasha Warner, Jocelyn Ahlers, Leela Bilmes, Monica Oliver, Suzanne Wertheim, \& Melinda Chen (eds.), Gender and belief systems, 183-90. Berkeley: Berkeley Women and Language Group.

(2000). Linguistic variation as social practice: The linguistic construction of identity in Belten High. Oxford: Blackwell.

(2008). Variation and the indexical field. Journal of Sociolinguistics 12:453-76.

(2012). Three waves of variation study: The emergence of meaning in the study of sociolinguistic variation. Annual Review of Anthropology 41:87-100.

Edwards, John (1999). Refining our understanding of language attitudes. Journal of Language and Social Psychology 18:101-10.

Fazio, Russell; David Sanbonmatsu; Martha Powell; \& Frank Kardes (1986). On the automatic activation of attitudes. Journal of Personality and Social Psychology 50:229-38.

Foulkes, Paul (2010). Exploring social-indexical knowledge: A long past but a short history. Laboratory Phonology 1:5-39.

Gaudio, Rudolf (1994). Sounding gay: Pitch properties in the speech of gay and straight men. American Speech 69:30-57.

Greenwald, Anthony; Debbie McGhee; \& Jordan Schwartz (1998). Measuring individual differences in implicit cognition: The implicit association test. Journal of Personality and Social Psychology 74:1464-80.

; Mahzarin Banaji; Laurie Rudman; Shelly Farnham; Brian Nosek; \& Deborah Mellot (2002). A unified theory of implicit attitudes: Stereotypes, self-esteem and self-concept. Psychological Review 109:3-25.

Guy, Gregory (1993). The quantitative analysis of linguistic variation. In Dennis Preston (ed.), American dialect research, 223-49. Amsterdam: John Benjamins.

Hay, Jennifer; Paul Warren; \& Katie Drager (2006). Factors influencing speech perception in the context of a merger in progress. Journal of Phonetics 34:458-84.

Higgins, E. Tory, \& John Bargh (1987). Social cognition and social perception. Annual Review of Psychology 38:369-425.

Johnson, Keith; Elizabeth Strand; \& Mariapaola D'Imperio (1999). Auditory-visual integration of talker gender in vowel perception. Journal of Phonetics 27:359-84.

Johnstone, Barbara, \& Scott Kiesling (2008). Indexicality and experience: Exploring the meanings of /aw/-monophthongization in Pittsburgh. Journal of Sociolinguistics 12:5-33.

Keogh, Peter; Catherine Dodds; \& Laurie Henderson (1994). Working class gay men: Redefining community, restoring identity. London: Sigma Research.

Kerswill, Paul (2003). Dialect levelling and geographical diffusion in British English. In David Britain \& Jenny Cheshire (eds.), Social dialectology, 223-43. Amsterdam: John Benjamins.

Lakoff, Robin (1975). Language and women's place. Cambridge: Cambridge University Press.

Levon, Erez (2006). Hearing 'gay': Prosody, interpretation and the affective judgment of men's speech. American Speech 81:56-78.

(2007). Sexuality in context: Variation and the sociolinguistic perception of identity. Language in Society 36:533-54.

Macrae, C. Neil, \& Galen Bodenhausen (2001). Social cognition: Categorical person perception. British Journal of Psychology 92:239-55.

Mann, Stephen (2012). Speaker attitude as a predictive factor in listener perception of gay men's speech. Journal of Language and Sexuality 1:205-29. 


\section{THE LINGUISTIC PERCEPTION OF SEXUALITY}

Miller, George, \& Patricia Nicely (1955). An analysis of perceptual confusion among some English consonants. Journal of the Acoustical Society of America 27:338-52.

Milroy, Lesley (2004). Language ideologies and linguistic change. In Carmen Fought (ed.), Sociolinguistic variation: Critical reflections, 161-77. Oxford: Oxford University Press.

Mosse, George (1985). Nationalism and sexuality: Middle-class morality and sexual norms in modern Europe. Madison: University of Wisconsin Press.

Munson, Benjamin (2007). The acoustic correlates of perceived sexual orientation, perceived masculinity and perceived femininity. Language and Speech 50:125-42.

— \& Molly Babel (2007). Loose lips and silver tongues, or, projecting sexual orientation through speech. Language and Linguistics Compass 1:416-49.

— Elizabeth McDonald; Nancy DeBoe; \& Aubrey White (2006). The acoustic and perceptual bases of judgments of women's and men's sexual orientation from read speech. Journal of Phonetics 34:202-40.

Niedzielski, Nancy (1999). The effect of social information on the perception of sociolinguistic variables. Journal of Language and Social Psychology 18:62-85.

Nosofsky, Robert (1986). Attention, similarity and the identification-categorization relationship. Journal of Experimental Psychology: General 115:39-57.

Nusbaum, Howard, \& Todd Morin (1992). Paying attention to differences among talkers. In Yoh'ichi Tohkura, Eric Vatikiotis-Bateson, \& Yoshinori Sagisaka (eds.), Speech perception, production and linguistic structure, 113-34. Amsterdam: IOS Press.

Pendry, Louise, \& C. Neil Macrae (1996). What the disinterested perceiver overlooks: Goal-directed social categorization. Personality and Social Psychology Bulletin 22:249-56.

Pharao, Nicolai; Marie Maegaard; Janus Møller; \& Tore Kristiansen (2014). Indexical meanings of [s +] among Copenhagen youth: Social perception of a phonetic variant in different linguistic contexts. Language in Society 43:1-31.

Pleck, Joseph; Freya Sonenstein; \& Leighton Ku (1993). Masculinity ideology and its correlates. In Stuart Oskamp \& Mark Constanzo (eds.), Gender issues in contemporary society, 85-110. London: Sage.

— F Freya Sonenstein; \& Leighton Ku (1994). Attitudes towards male roles among adolescent males: A discriminant validity analysis. Sex Roles 30:481-501.

Podesva, Robert (2007). Phonation type as a stylistic variable: The use of falsetto in constructing a persona. Journal of Sociolinguistics 11:478-504.

Preston, Dennis (2010). Variation in language regard. In Peter Gilles, Joachim Scharloth, \&Evelyn Zeigler (eds.), Empirische Evidenzen Und Theoretische Passungen Sprachlicher Variation, 7-27. Frankfurt: Peter Lang.

(2011). The power of language regard: Discrimination, classification, comprehension and production. Dialectologia (Special issue) 2:9-33.

Ricketts, Wendell, \& Walter Hudson (1998). Index of homophobia. In William Yarber, Robert Bauserman, \& George Schreer (eds.), Handbook of sexuality-related measures, 367-68. London: Sage.

Scherer, Klaus (1972). Judging personality from voice: A cross-cultural approach to an old issue in interpersonal perception. Journal of Personality 40:191-210.

Seidman, Steven (2002). Beyond the closet: The transformation of gay and lesbian life. London: Routledge.

Silverstein, Michael (1979). Language structure and linguistic ideology. In Paul Clyne, William Hanks, \& Carol Hofbauer (eds.), The elements: A parasession on linguistic units and levels, 193-247. Chicago: Chicago Linguistics Society.

Smyth, Ron; Greg Jacobs; \& Henry Rogers (2003). Male voices and perceived sexual orientation: An experimental and theoretical approach. Language in Society 32:329-50.

Stuart-Smith, Jane, \& Claire Timmins (2006). 'Tell her to shut her moof': The role of the lexicon in THfronting in Glaswegian. In Graham Caie, Carole Hough, \& Irené Wotherspoon (eds.), The power of words: Essays in lexicography, lexicology and semantics, 171-83. Amsterdam: Rodopi. 


\section{EREZ LEVON}

Wigboldus, Daniel; Ap Dijksterhuis; \& Ad van Knippenberg (2003). When stereotypes get in the way: Stereotypes obstruct stereotype-inconsistent trait inferences. Journal of Personality and Social Psychology 84:470-84.

Woolard, Kathryn (2008). Why dat now? Linguistic-anthropological contributions to the explanation of sociolinguistic icons and change. Journal of Sociolinguistics 12:432-52.

Wyer, Robert (ed.) (1998). Stereotype activation and inhibition. (Advances in social cognition 11.) New York: Psychology Press.

Yaeger-Dror, Malcah (1993). Linguistic analysis of dialect 'correction' and its interaction with cognitive salience. Language Variation and Change 5:189-224.

Zimman, Lal (2013). Hegemonic masculinity and the variability of gay-sounding speech. Journal of Language and Sexuality 2:1-39.

(Received 10 February 2013; revision received 9 June 2014; accepted 10 June 2014; final revision received 1 July 2014) 